\title{
Rancang Bangun Sistem Otomatisasi Waktu Penangkaran Burung Walet Berbasis Mikrokontroller
}

\author{
Ikhsan \\ Manajemen Informatika, AMIK Jayanusa Padang, email : riksjp21@gmail.com
}

\begin{abstract}
Swallow cultivation is excellent for some farmers, because Swallow's nest can become a new commodity. Most of the swallow cultivators make swallow house either at home or elsewhere. To provoke this type of bird to come and nest on the home made, calling technique is required. Technique, played the audio Swallow as a means of caller. However, this sound does not have to be played at all times, there are certain hours, so it will take more time and energy to turn on it many times every day. Although the market has many types of bird sounds are packed in the form of twitter, but the price is still too high. For this time automation system has an important role for the process of on / off audio Swallow can be organized well. The design is done by research method with the steps as follows: Field Research, Interview, Research Library, and last Research Laboratory. The result; The system can play swift sounds stored in a Voice IC based on pre-set time, so it can time to turn on and off the Swallow's voice, besides, this automation system can also cost efficiency when compared to buying automatic twitter.
\end{abstract}

Keywords: Automatitation System, Swallow, Mikrocontroller

\begin{abstract}
Abstrak
Budidaya Walet menjadi primadona bagi sebagian kalangan masyarakat pembudidaya, karena sarang Walet dapat menjadi komoditas baru. Sebagian besar para pembudidaya walet membuat rumah burung walet (RBW) baik di rumahnya maupun ditempat lain. Untuk memancing jenis burung ini agar datang dan bersarang pada rumah yang dibuat, dibutuhkan teknik pemanggil. Tekniknya, diputarkan audio burung Walet sebagai sarana pemanggilnya. Namun, suara ini tidak harus diperdengarkan setiap saat, ada jam-jam tertentu, sehingga akan membutuhkan waktu dan tenaga lebih untuk menghidupkan berkali-kali setiap hari. Walaupun dipasaran sudah banyak jenis suara burung yang dikemas dalam bentuk twitter, namun harganya masih terlalu tinggi. Untuk itu sistem otomatisasi waktu ini memiliki peranan penting agar proses on/off audio Walet dapat terorganisir dengan baik. Perancangan dilakukan dengan metode penelitian dengan langkah-langkah sebagai berikut : Penelitian Lapangan, Wawancara, Penelitian Pustaka, dan terakhir Penelitian Laboratorium. Hasilnya; sistem ini dapat berjalan memainkan suara walet yang disimpan dalam sebuah IC Suara berdasarkan waktu yang sudah diset sebelumnya, sehingga dapat mengefesienkan waktu untuk menghidupkan dan mematikan suara burung Walet, disamping itu, sistem otomatisasi ini juga dapat mengefesienkan biaya jika dibandingkan dengan membeli twitter otomatis.
\end{abstract}

Kata kunci: Sistem Otomatisasi, Walet, Mikrokontroller.

(C) 2017 Jurnal RESTI

\section{Pendahuluan}

Burung Walet menjadi satu dari sekian banyak model binatang yang dipelihara untuk diambil hasilnya. Sehingga banyak yang membuat penangkaran di berbagai tempat agar dapat menghasilkan sarangnya. Sarang inilah yang menjadi nilai ekonomis. Banyak jenis makanan dan minuman yang berasal dari sarang burung walet ini. Selain dimanfaatkan untuk makanan dan minuman, ternyata sarang ini juga dipercaya memiliki berbagai macam khasiat, oleh sebab itulah nilai sarang burung walet ini di pasaran lumayan mahal, sehingga menggiurkan para pelaku untuk membudidayakan burung walet ini.

Sebelumnya, para pembudidaya sarang burung wallet, mencari sarangnya pada goa-goa, pada pohon-pohon, dan pada tempat-tepat lain yang aman di dalam hutan. Kegiatan ini dilakukan per 3-5 bulan sekali. Proses memanen sarang di dalam hutan ini beresiko tinggi, ditambah lagi kemungkinan tidak didapatkannya sarang burung walet, sehingga proses mencari sarang di dalam hutan ini digantikan dengan membuat penangkaran sendiri, dengan cara membangun rumah tinggi ataupun 
rumah pohon tempat berdiam dan bersarangnya burung walet.

Untuk memanggil burung ini agar bisa bersarang pada penangkaran, maka dibuatlah sebuah suara-suara yang berasal dari burung walet, sehingga membuat burung walet lainnya tertarik untuk mendekat.

Para pembudidaya membunyikan suara lewat tape recorder yang diputar pada saat sore hari. Sehingga harus membuat pembudidaya datang ke penangkaran hanya untuk menghidupkan dan mematikan tape recorder.

Agar media pemanggil ini (suara burung) bisa diputar secara otomatis, maka diperlukanlah sebuah sistem otomatisasi yang bertugas untuk mengatur waktu putar dan waktu mematikan suara. Sehingga pembudidaya tidak perlu mengecek setiap saat tape recordernya.

\section{Tinjauan Pustaka}

\subsection{Walet}

Burung walet dengan Bahasa latin (Aerodramus fuciphagus) merupakan sumber daya hayati yang beredar di Asia Tenggara (Chantler \& Drienssens, 1995). Burung walet menghasilkan sarang yang banyak dicari orang, karena memang dipercaya memiliki khasiat. Faktanya, khasiat sarang burung walet ini sudah diketahui semenjak Dinasti Tang (618-907) sampai dinasti Sung (960-1279). Dari data Koon \& Cranbrook (2002) Penduduk Hongkong mengkonsumsi sarang walet 100 ton per tahun yang mendekati $60 \%$ suplai dunia. Komunitas Tionghoa di Amerika Utara mengkonsumsi 30 ton pertahun. Sedangkan penduduk di Cina daratan hanya 10 ton pertahun [1]. Bentuk sarang burung wallet yang belum diolah seperti pada Gambar 1

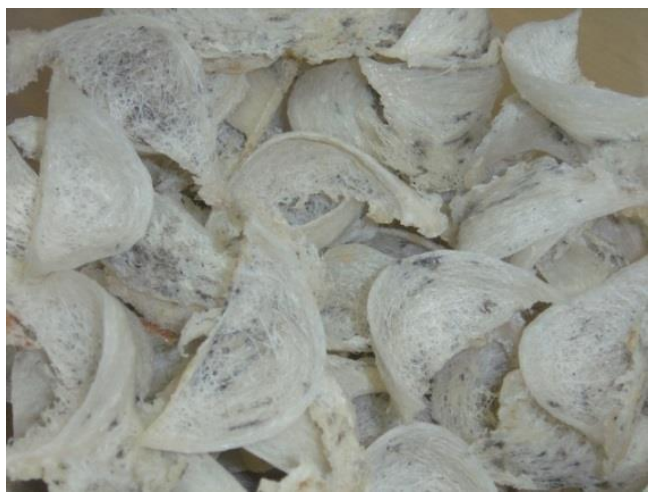

Gambar 1. Bentuk Sarang Burung Walet keabu-abuan lebih coklat, iris mata coklat tua, paruh dan kaki berwarna hitam (Mackinnon et al 1993). Sementara Collocalia linchi merupakan spesies endemik dataran sunda, hampir mirip dengan Collocalia fuciphaga tetapi ukurannya lebih kecil dengan panjang tubuh $9.41 \mathrm{~cm}$ dan pada bagian perut berwarna putih. Jenis dari burung walet seperti pada Gambar 2.

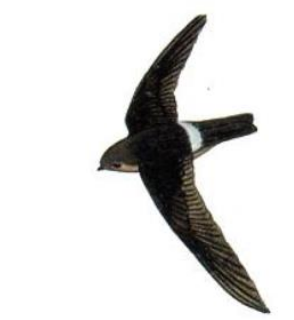

Collocalia fuciphaga (Burung walet sarang putih)

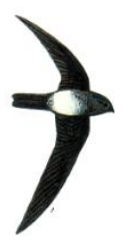

Collocalia linchi

(Burung walet sarang rumput)
Gambar 2. Jenis Burung Walet

Budidaya sarang burung walet menjadi primadona bagi sebagian besar rakyat Indonesia. Ada banyak faktor pembudidayaan burung walet ini, seperti : lokasi, iklim, lingkungan, faktor makanan, faktor bangunan, dan teknik memancing walet. Banyak masyarakat yang memiliki jiwa bisnis ikut mendirikan bangunan untuk dijadikan sebagai penangkaran burung walet. [3]. Rumah burung walet yang dijadikan penangkaran lihat Gambar 3.

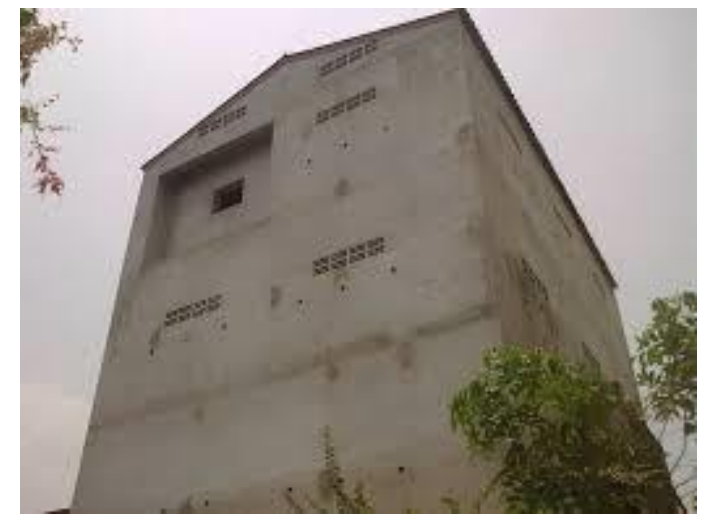

Gambar 3. Penangkaran Burung Walet

Dari beberapa faktor di atas, teknik memancing walet inilah yang coba dibahas dengan membuat model teknik memancing dengan suara burung walet yang hidup dan matinya suara berdasarkan waktu yang ditentukan dan dikendalikan oleh mikrokontroller.

Burung wallet yang dibudidayakan berdasarakan 2.2 Organisasi Naskah penelitian [2], ada 2 jenis, yaitu Collocalia fuciphaga Mikrokontroler merupakan suatu keping IC dimana (burung walet sarang putih) dan Collocalia linchi terdapat mikroprosesor dan memori program ROM (burung walet sarang rumput). Collocalia fuciphaga (Read Only Memory) serta memori serba guna RAM memiliki ciri berukuran agak kecil $(12 \mathrm{~cm}$ ) dengan (Random Acses Memory) bahkan ada beberapa jenis tubuh bagian atas coklat kehitaman, tunggir coklat atau mikrokontroler yang memiliki fasilitas $A D C, P L L$, 
EEPROM dalam satu kemasan. Penggunaan berjumlah 8 pin. [8]. Rangkaian matrix keypad 4x4 mikrokontroler dalam bidang kontrol sangat luas dan lihat Gambar 6.

popular [4]. Bentuk IC Mikrokontroller Atmega 16, lihat gambar 4.

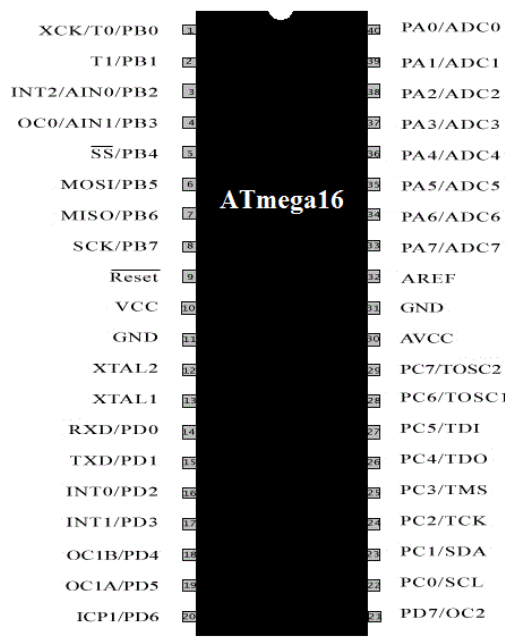

Gambar 4. Mikrokontroller Atmega26

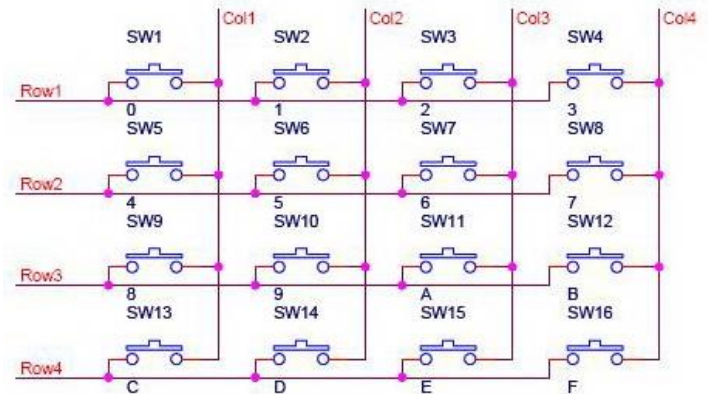

Gambar 6. Matrix Keypad 4x4

\subsection{ISD 25120}

ISD 25120 adalah single-chip dengan kualitas tinggi, dengan durasi rekam atau putar ulang (Record/Playback) antara 60 sampai 120 detik. Merupakan komponen CMOS yang terdiri atas on-chip oscillator, microphon preamplifier, aoutomatic gain control, antialiasing filter, smoothing filter, speaker Mikrokontroler ATmega16 digunakan untuk preamplifier, dan high density multilevel storage array. pengolahan data-data biner (digital) yang di dalamnya [9]. Bentuk ISD 25120 lihat Gambar 7. merupakan gabungan dari rangkaian-rangkaian elektronik yang dikemas dalam suatu chip IC (Integrated Circuit). [5]. Mikrokontroller ini memiliki 21 pin yang dibagi menjadi 4 port.

\section{$2.3 \mathrm{LCD}$}

LCD atau monitor digunakan untuk melihat tampilan interval dan waktu yang sedang berjalan. Monitor ini digunakan hanya untuk memudahkan mengecek sistem kontrol atau sistem keamanan jika sistem berjalan tidak sesuai dengan yang diharapkan. [6]

Menurut [7] yang dikutip dari Delta Elektronik, M1632 Module LCD 16x2 Baris, LCD adalah suatu jenis media penampil yang menggunakan kristal cair sebagai penampil utama. Pada lcd berwarna semacam monitor,
terdapat banyak sekali titik cahaya. Bentuk konfigurasi LCD, lihat Gambar 5.

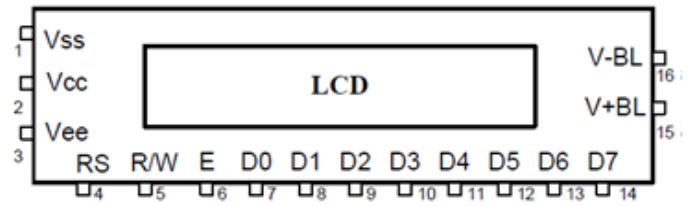

Gambar 5. Konfigurasi Pin LCD 16x2

\subsection{Keypad}

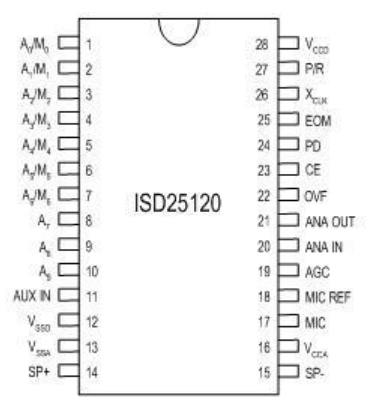

Gambar 7. Pin ISD25120

\subsection{Catu daya}

Pada sistem ini, dibutuhkan catu daya sebagai sumber tegangan. Karena sistem ini menggunakan model arus searah (DC) maka dibentuklah catu daya yang menyuplai tegangan AC ke DC. Seperti yang dijelaskan pada [10]. Fungsi penyearah atau rectifier didalam rangkaian catu daya adalah untuk mengubah tegangan listrik AC yang berasal dari trafo stepdown atau trafo adaptor menjadi tegangan listrik arus searah. Pada umumnya tegangan yang dihasilkan oleh rangkaian rectifier.

\subsection{Speaker}

Speaker difungsikan untuk mengeluarkan suara burung Keypad adalah rangkaian tombol yang berfungsi untuk walet yang sudah direkam dalam IC Suara ISD 25120. memberi sinyal pada suatu rangkaian dengan Karena sifatnya yang merubah sinyal elektrik ke menghubungkan jalur-jalur tertentu. keypad matriks $4 \mathrm{x}$ frekuensi audio. Sehingga suara walet bisa terdengar 4 (16 push button) dengan pin penghubung rangkaian lebih keras. Contoh speaker lihat Gambar 8.

Jurnal RESTI (Rekayasa Sistem dan Teknologi Informasi) Vol. 1 No. 1 (2017) 43 - 49 


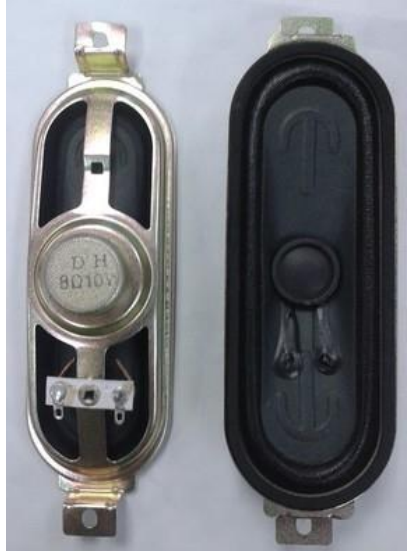

Gambar 8. Speaker

\section{Metodologi Penelitian}

Metode penelitian yang digunakan dalam proses dapat dilihat pada bagan Gambar 9 :

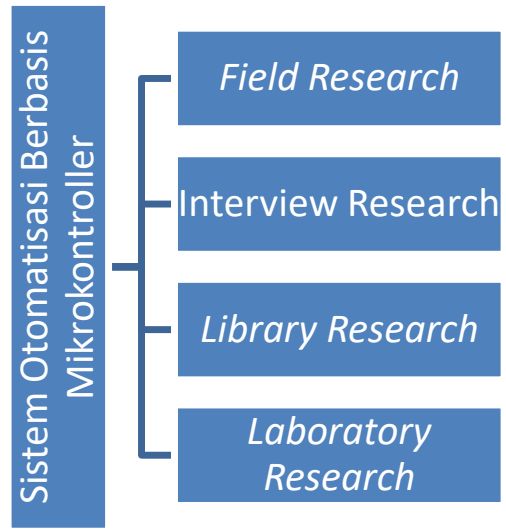

Gambar 9. Alur Kerja Penelitian

Dari Alur diatas dapat digambarkan bahwasanya penelitian ini dimulai dari Field Research. Dimana penelitian ini mengecek langsung seperti apa proses penangkaran dan penyalaan suara untuk memanggil (memancing) burung walet. Sekalian melakukan Interview Research, dimana dalam proses interview ini responden adalah orang yang bergiat pada budidaya walet ini bertahun-tahun. Pak Mettoni yang bertempat tinggal di Kalawi kota Padang, selaku responden yang memaparkan banyak hal mengenai teknik memanggil suara burung walet ini, mulai dari seperti apa suara pemanggil yang dipakai, sampai waktu-waktu yang bagus untuk memutarkan suaranya. Selanjutnya dilakukan Library Research dengan mencari bahan dan kepustakaan mengenai apa saja yang berhubungan dengan penelitian ini. Dan terakhir dari proses kerjanya adalah Laboratory Research, dimana sistem ini mulai dirancang, dibangun, dan diuji, apakah berjalan seperti yang diharapkan. Terakhir, cek dan bandingkan dengan alat otomatis sejenis yang beredar dipasaran.

\section{Hasil dan Pembahasan}

\subsection{Perancangan Sistem}

Untuk memudahkan dalam membuat perancangan sistem penangkaran burung walet berbasis mikrokontroler, maka dibuat gambaran tentang kerja sistem dalam bentuk blok diagram. Blok diagram merupakan gambaran singkat dari perancangan suatu sistem, dari blok diagram dapat diketahui cara kerja rangkaian keseluruhan, sehingga keseluruhan blok diagram akan menghasilkan suatu sistem yang dapat difungsikan dan dapat berkerja sesuai dengan yang diharapkan. Blog diagram sistem yang dirancang lihat Gambar 10.

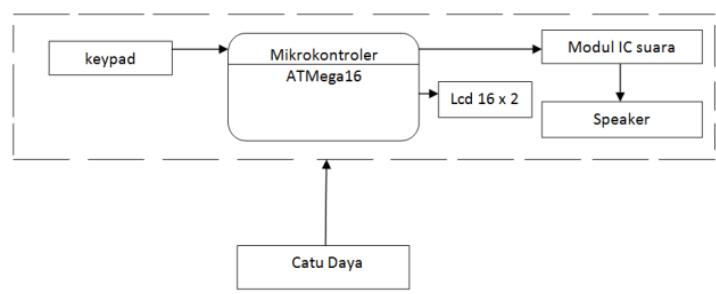

Gambar 10.Blok Diagram Sistem

\subsubsection{Rangkaian Minimum Sistem Atmega16}

Sistem minimum mikrokontroler ATMega16 merupakan rangkaian minimum yang dibuat agar mikrokontroler ini dapat bekerja dan berfungsi dengan semestinya. Sistem minimum ini meliputi kristal oscillator (opsional) yang berfungsi sebagai referensi kecepatan akses mikrokontroler, tombol reset, serta port-port I/O. Pada port $\mathrm{D}$ adalah input yang menghubungkan pin dengan keypad, port $\mathrm{C}$ sebagai output yang menghubungkan pin dengan LCD dan port A adalah output yang terhubung dengan IC suara. Rangkaian minimum sistem, lihat Gambar 11.

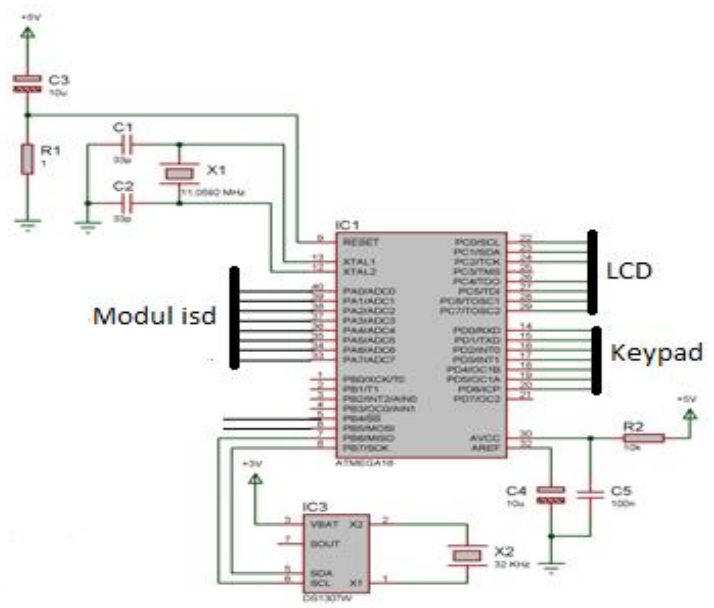

Gambar 11. Rangkaian Minimum Sistem

Hasil pengukuran dari masing-masing modul yang terhubung pada minimum sistem, lihat Tabel 1. 
Tabel 1. Input/Ouput Ke Mikrokontroller

\begin{tabular}{llllll}
\hline No & I/O & Port & $\begin{array}{l}\text { Tega } \\
\text { ngan }\end{array}$ & \multicolumn{2}{c}{ Keteranagan } \\
\hline 1. & $\begin{array}{l}\text { Keypad } \\
3 \times 4\end{array}$ & $\begin{array}{l}\text { PD0- } \\
\text { PD7 }\end{array}$ & $0-5 \mathrm{~V}$ & $\begin{array}{l}\text { Input ke mikro } \\
\text { berupa logika High } \\
\text { atau Low }\end{array}$ \\
2. & $\begin{array}{l}\text { IC suara } \\
\text { 25120 }\end{array}$ & $\begin{array}{l}\text { PA0- } \\
\text { PA7 }\end{array}$ & $0-5 \mathrm{~V}$ & $\begin{array}{l}\text { Output } \\
\text { tegangan } \\
\text { mikrokontroler }\end{array}$ \\
3. & Lcd 16x2 & $\begin{array}{l}\text { PC0- } \\
\text { PC2 } \\
\text { PC4- }\end{array}$ & $0-5 \mathrm{~V}$ & $\begin{array}{l}\text { Output mikro berupa } \\
\text { display waktu }\end{array}$ \\
& & & & \\
\hline
\end{tabular}

Dari Tabel 1 dapat dijelaskan bahwa Pengujian terhadap mikrokontroler ATMega16 pada PD0-PD7 diset sebagai input berlogika high "1" jika ada penekanan terhadap keypad dan tegangan yang dihasilkan 5 volt, sebaliknya jika berlogika low "0" tegangan yang dihasilkan 0,2 volt.

\subsubsection{Rangkaian LCD}

Rangkaian LCD dimanfaatkan untuk menampilkan karakter, sehingga akan mempermudah dalam mensetting waktu. LCD yang digunakan adalah LCD $16 \times 2$. Rangkaian LCD, tampak pada Gambar 12 .

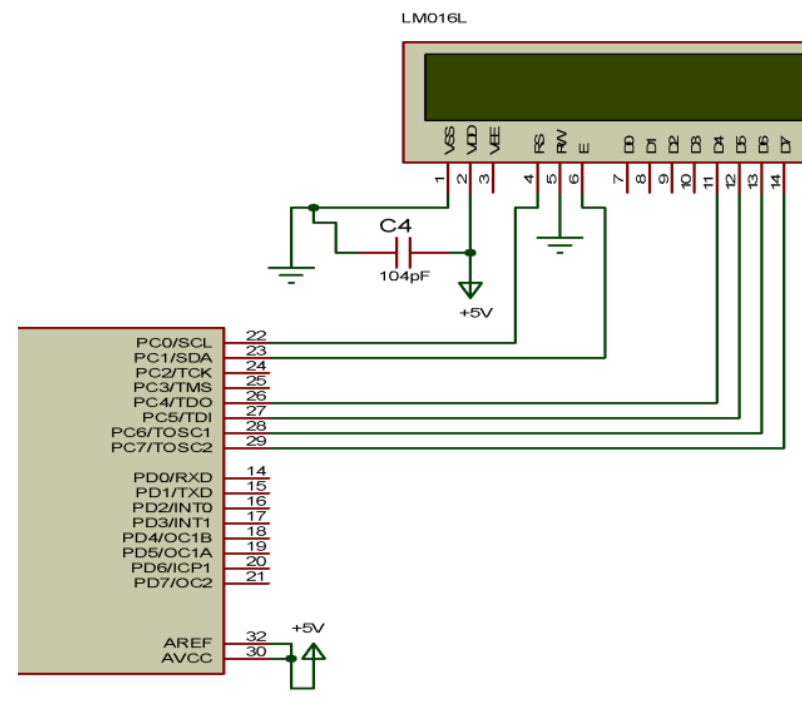

Gambar 12. Rangkaian LCD

Untuk pengujian LCD yaitu bagaimana LCD dapat menampilkan data karakter yang dibuat pada program dalam mikrokontroler dan menampilkan waktu secara digital. Hasil tampilan LCD, lihat Gambar 13.

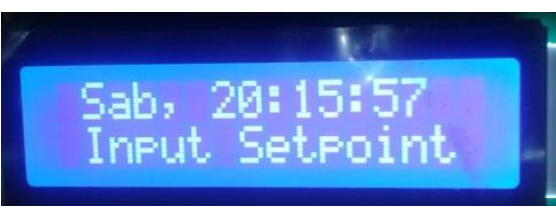

Gambar 13. Tampilan LCD
"Waktu Proses", dan sebaliknya keypad tidak mengirim sinyal ke mikrokontroler, maka LCD nonaktif.

\subsubsection{Rankaian IC Suara (ISD 25120)}

Untuk rangkaian output suara digunakan rangkaian dari IC single chip recorder dari ISD yaitu ISD 25120. Kegunaan dari IC ini cukup banyak salah satunya adalah kemampuan untuk menyimpan multiple messages. Rangkaian pengisi suara, lihat Gambar 14.

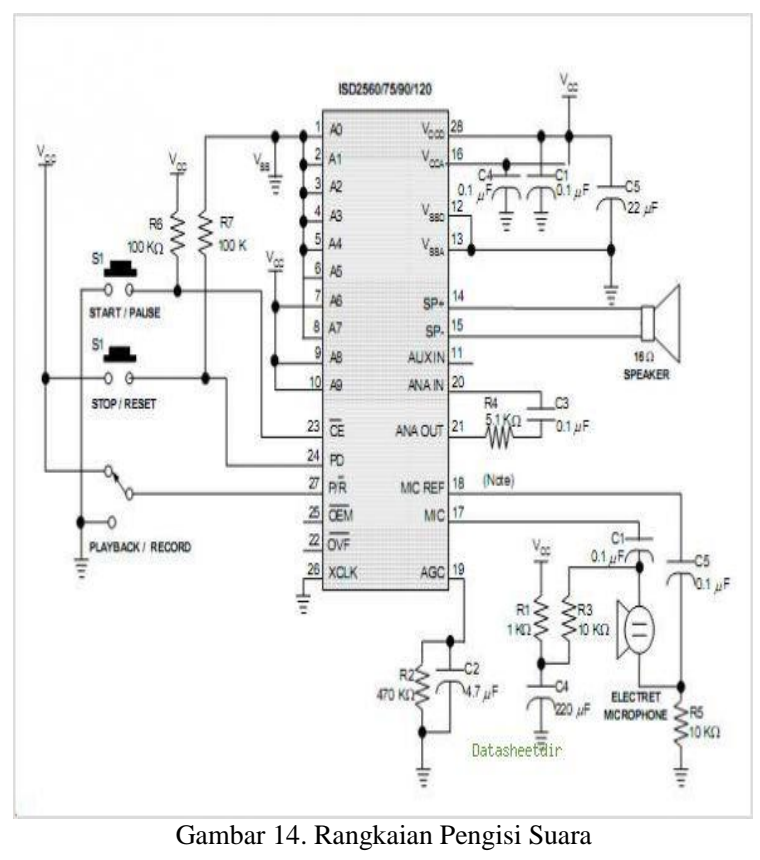

Alamat-alamat suara yang dipakai beserta dengan pesan suara yang tersimpan di dalamnya, pesan-pesan inilah yang akan di playback pada saat penekanan atau kombinasi switch saat ditekan. Dan untuk penguatan suara ke speaker menggunakan IC amplifier LM386 dengan penguatan 20 sampai 200 kali.

Pengujian pertama terhadap modul ISD 25120 yakni dengan cara manual yaitu memberikan tegangan sebesar 5 volt (dengan range 2,4-5,5 V), kemudian dilakukan perekaman suara dengan cara menekan tombol REC/RECORD (pin 27) dengan durasi maksimal 120 detik melalui $M I C$, setelah selesai lepaskan tombol $R E C$, dan untuk menghidupkan suara yang telah direkam ke dalam flash memori ISD 25120 dengan cara menekan tombol PLAY (pin 23), sedangkan untuk menghapus suara yang telah direkam dengan cara menekan tombol ERASE (pin 24) dan output dihubungkan ke sebuah speaker untuk menampilkan suara yang telah direkam. Tampilan hasil pengujian, lihat Gambar 15.

Pengujian kedua dengan menghubungkan modul ISD 25120 ke mikrokontroller (sistem minimum ATMega16) yaitu melalui Pin kontrol untuk perintah LCD menampilkan tampilan output, keypad mengirim dari mikrokontroler melalui komunikasi SPI pada ISD sinyal ke mikrokontroler, maka LCD menampilkan 25120. 


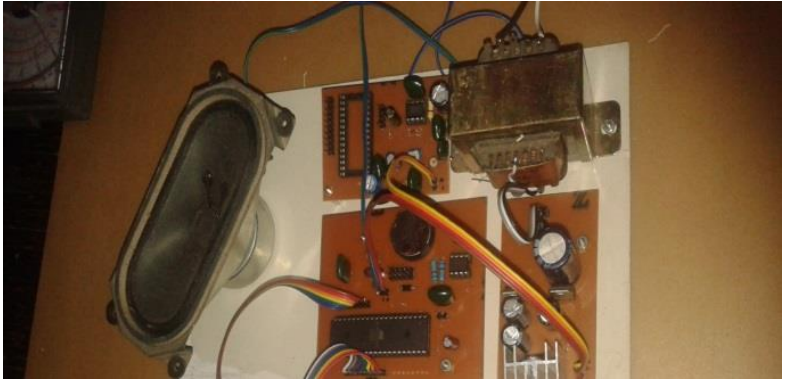

Gambar 15. Pengujian ISD 25120

\subsubsection{Rangkaian Keypad}

Rangkaian Keypad ini yang berfungsi untuk mengentrikan nilai waktu. Jadi sistem dapat melakukan fungsi untuk memanggil kapan suara dinyalakan, dan dimatikan sesuai yang dientrikan pada keypad. Gambar rangkaian Keypad pada sistem ini, lihat Gambar 16, dan hasil pengujian, lihat Tabel 2.

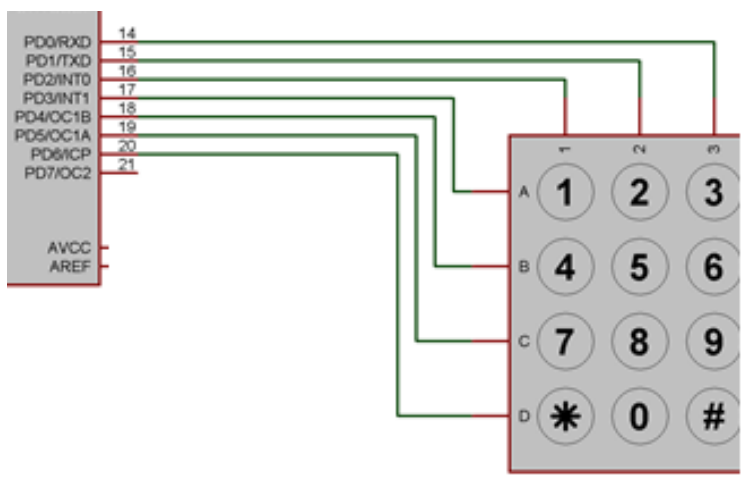

Gambar 16. Rangkaian Keypad

Tabel 2 Tabel Keluaran Tegangan Keypad

\begin{tabular}{lll}
\hline \multicolumn{1}{c}{ Kondisi } & Tegangan & \multicolumn{1}{c}{ Keterangan } \\
Keypad & & \\
\hline Tidak Ditekan & $5 \mathrm{~V}$ & Keypad tidak mengirim sinyal ke mikro \\
Ditekan & $0 \mathrm{~V}$ & Keypad mengirim Sinyal ke mikro \\
\hline
\end{tabular}

\subsubsection{Flowchart}

Agar modul program yang dirancang memiliki struktur dengan kualitas yang baik, maka perlu diawali dengan penentuan logika program, lihat gambar 17.

\subsubsection{Hasil Keseluruhan}

Dari sub rangkaian pada pembahasan diatas, maka tersusun rangkaian keseluruahan sistem, lihat gambar 18.

Sistem dapat bekerja dengan baik secara keseluruhan. IC suara berhasil mengeluarkan suara burung walet selama range waktu dari jam 16.00 - 18.00 WIB (waktu yang diberikan saat pengujian), sesuai dengan logika yang diberikan. IC suara ISD 25120 berbunyi kehandalan sistem otomatisasi ini dibandingkan dengan sesuai instruksi yang diberikan oleh program. Dan yang beredar seperti yang terangkum dalam Tabel 3. hanya membutuhkan 1 catudaya sebagai penyuplai tegangan.

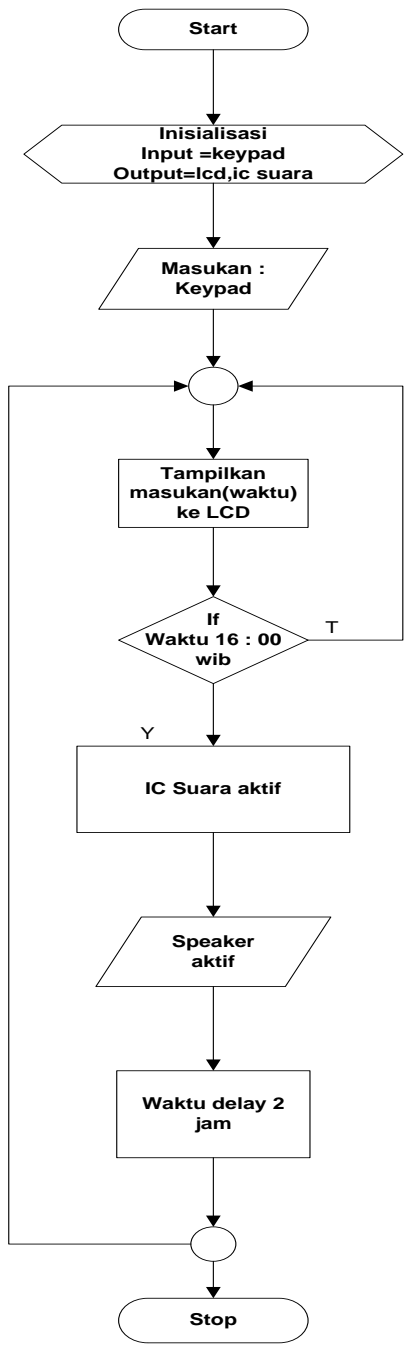

Gambar 17. Flowchart Sistem Waktu Otomatis Penangkaran

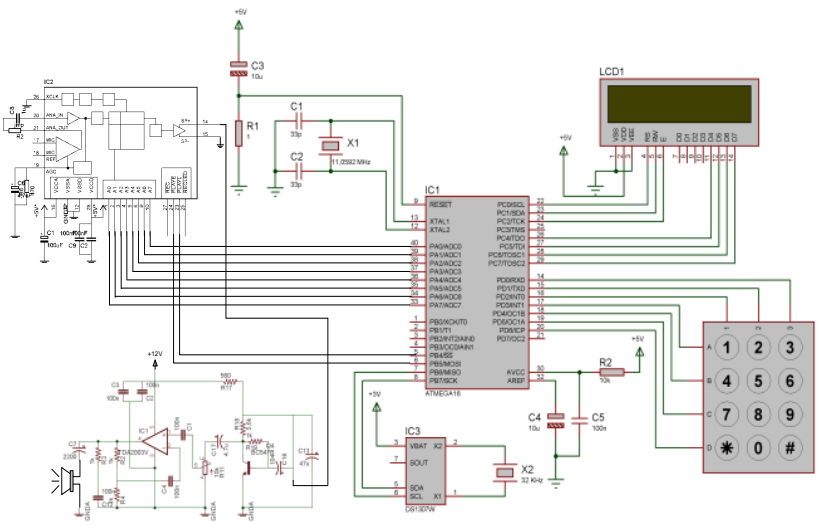

Gambar 18. Rangkaian Sistem Waktu Otomatis Penangkaran
Dari hasil perancangan dan ujicoba implementasi serta wawancara dengan narasumber, ada temuan 
Tabel 3 Tabel Perbandingan Sistem dengan Twitter

\begin{tabular}{|c|c|c|c|}
\hline & $\begin{array}{l}\text { Sistem } \\
\text { Otomatisasi }\end{array}$ & $\begin{array}{l}\text { Twitter } \\
\text { Menegah }\end{array}$ & $\begin{array}{l}\text { Twitter } \\
\text { Bagus }\end{array}$ \\
\hline $\begin{array}{l}\text { Harga } \\
\text { (dalam } \\
\text { rupiah) }\end{array}$ & $<700.000$ & $\begin{array}{l}400.000- \\
1.000 .000\end{array}$ & $>1.000 .000$ \\
\hline Pemasangan & Mudah & $\begin{array}{l}\text { Mudah - } \\
\text { Lumayan }\end{array}$ & $\begin{array}{l}\text { Lumayan } \\
\text { membutuhk } \\
\text { an ahli }\end{array}$ \\
\hline $\begin{array}{l}\text { Penambahan } \\
\text { Suara }\end{array}$ & Bisa & Bisa & Bisa \\
\hline $\begin{array}{l}\text { Komponen } \\
\text { Elektronika }\end{array}$ & Simple & $\begin{array}{l}\text { Simle } \quad- \\
\text { Rumit }\end{array}$ & Rumit \\
\hline $\begin{array}{l}\text { Proses } \\
\text { Penyalaan }\end{array}$ & Otomatis & $\begin{array}{l}\text { Manual - } \\
\text { otomatis }\end{array}$ & Otomatis \\
\hline $\begin{array}{ll}\text { Set } & \text { Waktu } \\
\text { Ulang } & \end{array}$ & Bisa & Bisa & Bisa \\
\hline $\begin{array}{l}\text { Cek } \\
\text { Kerusakan }\end{array}$ & $\begin{array}{l}\text { Mudah } \\
\text { (Karena } \\
\text { dibuat } \\
\text { Sendiri) }\end{array}$ & $\begin{array}{l}\text { Lumayan } \\
\text {-Susah }\end{array}$ & Susah \\
\hline
\end{tabular}

\section{Kesimpulan}

Setelah dilakukan penelitian terhadap sistem otomatisasi waktu penangkaran burung walet berbasis mikrokontroller ini, maka didapatkan hasil kesimpulan dan beberapa saran.

\subsection{Simpulan}

1. Data yang diperoleh pada saat melakukan pengujian, sistem ini dapat beroperasi dengan baik. Serta penyetingan waktu sesuai Real time dan suara walet dapat aktif berdasarkan waktu yang sudah ditentukan.

2. Dibandingkan dengan Twitter yang beredar dipasaran, sistem ini bisa dikatakan optimal jika mengukurnya dari segi biaya (harga), waktu, dan tenaga (jika harus bolak-balik menghidupkan dan mematikan suara burung walet di penangkaran).

\subsection{Saran}

Dari hasil penelitian sudah dipaparkan, namun masih banyak saran demi sempurnanya sistem ini. Sistem ini tidak disarakankan untuk pembudidaya walet yang memiliki skop besar, sistem ini dipakai untuk mencek, apakah lokasi tersebut sudah memungkinkan untuk membuat rumah walet, sehingga bisa dilanjutkan untuk membudidayakan walet. Jika ada walet yang mampir, sebaiknya sistem ini diganti dengan twitter walet yang sudah memiliki fitur lengkap dan memang dimanfaatkan untuk pemancing dari walet. Jika sistem ini dipakai untuk skop besar, maka harus ada perbaikan, seperti penambahan kualitas suara burung walet, penguat suara (amplifier), penyemprot air otomatis (untuk kelembapan rumah walet), pengaturan suhu, kebisingan, dan lain-lain. Sehingga semua fitur mikrokontroller dapat dimanfaakan dengan maksimal.

\section{Daftar Rujukan}

[1] D. Iriyani, "PENGARUH LAJU PENUMPUKAN DAN KELEMBABAN FESES BURUNG WALET (Aerodramus fuciphagus) PADA PERUBAHAN WARNA SARANG WALET," J. Mat. Sains, dan Teknol., vol. 13, no. Burung Walet, pp. 43-50, 2012.

[2] R. Margareta and M. Abdullah, "Pemodelan Spasial Habitat Burung Walet Sarang Putih Menggunakan Sistem Informasi Geografis (SIG) dalam Upaya Pengembangan Budidaya Sarang Walet di Jawa Tengah (Studi Kasus Kaupaten Grobogan dan Kabupaten Semarang)," J. Sains dan Teknol., vol. 8, no. 2, pp. 73-86, 2010

[3] D. Kurniati and E. Dolorosa, "Analisis Faktor Internal dan Eksternal Usaha Agribisnis Sarang Burung Walet di Kota Pontianak," J. Iprekas - Ilmu Pengetah. Rekayasa, no. Sarang Burung Walet, pp. 1-6, 2012.

[4] A. B. Santoso, Martinus, and Sugyanto, "Pembuatan Otomasi Pengaturan Kereta Api , Pengereman, Dan Palang Pintu Pada Rel Kereta Api Mainan Berbasis Mikrokontroler," J. FEMA, vol. 1, no. Januari 2013, pp. 16-23, 2013.

[5] T. Azwar and A. Kholiq, "Jurnal Inovasi Fisika Indonesia Vol . 02 No . 03 Tahun 201341 - 45 Anemometer Digital Berbasis Mikrokontroler Atmega-16 Abstrak," J. Inov. Fis. Indones., vol. 2, no. 3, pp. 1-5, 2013.

[6] Zulfikar, Zulhelmi, and K. Amri, "Desain sistem kontrol penyalaan lampu dan perangkat elektronik untuk meniru keberadaan penghuni rumah,” JNTE, vol. 5, no. Sistem Kontrol, 2016.

[7] I. Pracoyo Tribowo, S. Dwi Riyanto, and W. Hidayat, "Prototype Sistem Penerangan Lampu Otomatis Menggunakan DS1307 Berbasis Mikrokontroler Atmega16," J. INFOTEKMESIN, vol. 7, no. 1, pp. 78-87, 2014.

[8] R. Sulistyowati and D. D. Febriantoro, "PERANCANGAN PROTOTYPE SISTEM KONTROL DAN MONITORING PEMBATAS DAYA LISTRIK BERBASIS MIKROKONTROLER,” J. IPTEK, vol. 16, no. Sistem Kontrol, 2012.

[9] Y. Wiyandra and R. Sovia, "Rancangan Media Pembelajaran Pengenalan Huruf dan Angka Bagi Pendidikan Taman KanakKanak Didukung Mikrokontroler Atmega 128 dan IC Suara ISD25120 Dilengkapi Display Dot Matrik," vol. 5, no. 2, pp. 241-250, 2012.

[10] S. Anwar, Desmiwarman, and N. Nazaruddin, "Pemakaian Remote Control Tv Dengan Menggunakan Mikrokontroler At89S51 Sebagai Alat Pemutus Dan Penghubung Tegangan Kwh Meter 1 Phasa," Elektron, vol. 2, pp. 67-74, 2010. 